\title{
Laparoscopic appendectomy in a patient of 32 weeks gestational age

\author{
Surbhi Rathore ${ }^{1, *}$, Neelima $\mathrm{T}^{1}$ and Laxmikanth $\mathrm{T}^{2}$
}

'Department of Obstetrics and Gynaecology, Krishna Institute of Medical Sciences, Minister Road, Secunderabad-500003, Telangana, India ${ }^{2}$ Department of surgical gastroenterology, Krishna Institute of Medical Sciences, Minister Road, Secunderabad-500003, Telangana, India

\begin{abstract}
Most common non-obstetrical surgical emergency complicating pregnancy is acute appendicitis. Laparoscopic surgery for appendectomy in pregnant women is proving to be safe in all trimesters as surgical skills have increased, more experience has been gained and with more elegant instrumentation.
\end{abstract}

Keywords: laparoscopic; appendectomy; pregnancy

*Corresponding author: Dr. Surbhi Rathore, Department of Obstetrics and Gynaecology, Krishna Institute of Medical Sciences, Minister Road, Secunderabad-500003, Telangana, India. Mobile: 7673917788; Email: surbhirathore16@gmail.com

Received 20 December 2017; Revised 24 February 2017; Accepted 07 March 2017; Published 16 March 2017

Citation: Rathore S, Neelima T, Laxmikanth T. Laparoscopic appendectomy in a patient of 32 weeks gestational age. J Med Sci Res. 2017; 5(2):77-80. DOI: http://dx.doi.org/10.17727/ JMSR.2017/5-15

Copyright: (c) 2017 Rathore S et al. Published by KIMS Foundation and Research Center. This is an open-access article distributed under the terms of the Creative Commons Attribution License, which permits unrestricted use, distribution, and reproduction in any medium, provided the original author and source are credited.

\section{Introduction}

The most common non-obstetrical surgical emergencies complicating pregnancy are acute appendicitis, cholecystitis, and intestinal obstruction [1]. Approximately 1 in 500 to 1 in 635 women will require non-obstetrical abdominal surgery during their pregnancies $[1,2]$. Pregnancy used to be a relative contraindication to laparoscopy until recently because of the belief that it would decrease uterine and fetal blood flow and result in abortion or possibly affect fetal development. Concerns were raised about using laparoscopy specially after second trimester. Recently several reports of successful laparoscopic procedures in pregnancy have indicated the safety of laparoscopy in pregnancy $[3,4]$.

\section{Case report}

A30-year-old patient G2P1L1 with previous cesarean section with 32 weeks gestational age came to OPD with complaint of severe abdominal pain localized around umbilicus. Patient gave history of diffuse abdominal pain since two weeks, which became severe over last two days and was colicky in nature. 
Patient did not give any history of fever, vomiting, loss of appetite, bowel or bladder dys-function.

Patient was admitted at Krishna Institute of Medical Sciences, Secunderabad. Patients first and second trimester were uneventful. Patient was admitted at same hospital at 28 weeks gestational age with complaint of leaking per vaginum for observational. On speculum examination no leaking was observed, obstetric scan was done which was normal for gestational age and liquor was found to be adequate. Patient was discharged after giving steroid coverage with advice to have further regular antenatal visits.

Patients got first cesarean done at private hospital in view of relative cephalo pelvis disproportion, with uneventful intraoperative and postoperative period. Baby was $2.5 \mathrm{~kg}$ at birth and was active and healthy. Patient conceived spontaneously for second time after three years of last child birth.

There was no significant medical history or family history. Patient had only one surgery (cesarean section) in the past. On examination, patient was conscious and coherent, was in pain and was afebrile. Pulse rate was $105 / \mathrm{min}$, other vital parameters were within normal limit, urine protein was negative. Systemic examination was unremarkable. On inspection abdomen was distended. On palapationuterus was relaxed, symphysio fundal height corresponded to 32 weeks, with fetus in cephalic presentation. Fetal heart sound was heard on midpoint of left symphysio umbilical line. McBurneys and Rovsing signwere positive.

Patient was admitted for further evaluation. Obstetric and abdominal scanswere done which showed single live fetus corresponding to 32 weeks of gestation with normal doppler parameters with no evidence of retroplacental clot or free fluid in abdominal cavity and pelvis.

Complete blood picture was done which showed neutrophilia (73\%) with relative lymphopenia $(1 \%)$.

Surgical gastroenterologist was consulted, diagnosis of acute appendicitis was made and patient was planned for laparoscopic appendectomy. Preoperative evaluation was done, consent was taken and patient was prepared for surgery on next morning.

Patient was given general anaesthesia and was placed in low lithotomy position. First port (5 $\mathrm{mm})$, transumbilical wasinserted using Hasson technique, and was used as right hand port during procedure. Pneumoperitoneum was created with intraabdominal pressure of $12 \mathrm{~mm} \mathrm{Hg}$ with $\mathrm{CO}_{2}$ with an insufflator at $3 \mathrm{l} / \mathrm{min}$.

Patient was taken in $30^{\circ}$ left lateral position. Supra pubic port $(5 \mathrm{~mm})$ was inserted right of midline, avoiding injury to inferior epigastric vessels and used as camera port during procedure. Third $5 \mathrm{~mm}$ port was inserted along anterior axillary line at the base of appendix, under vision and was used as left hand port. During the period of anesthesia there were no periods of uterine activity.

The mesoappendixwas dissectedand the appendiceal artery was coagulated with harmonic scalpel and two catgut loops placed at distance of $5 \mathrm{~mm}$ at the base of appendix (Figure 1). Another loop was placed at a distance and appendix was cut between $2^{\text {nd }}$ and $3^{\text {rd }}$ loop with scissors. Inflamed appendix was removed by converting $5 \mathrm{~mm}$ umbilical port to $10 \mathrm{~mm}$ under vision (Figure 2). Previous LSCS scar was found to be healthy. Procedure was completed in $25 \mathrm{~min}$. Patient withstood the procedure well.

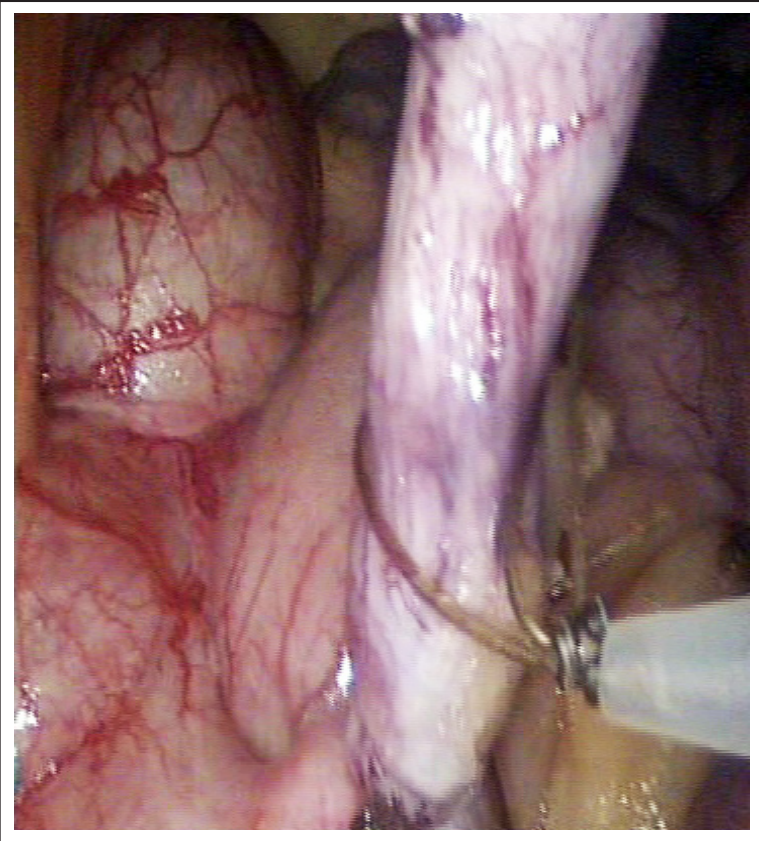

Figure 1: Catgut loop being applied at base of appendix. 


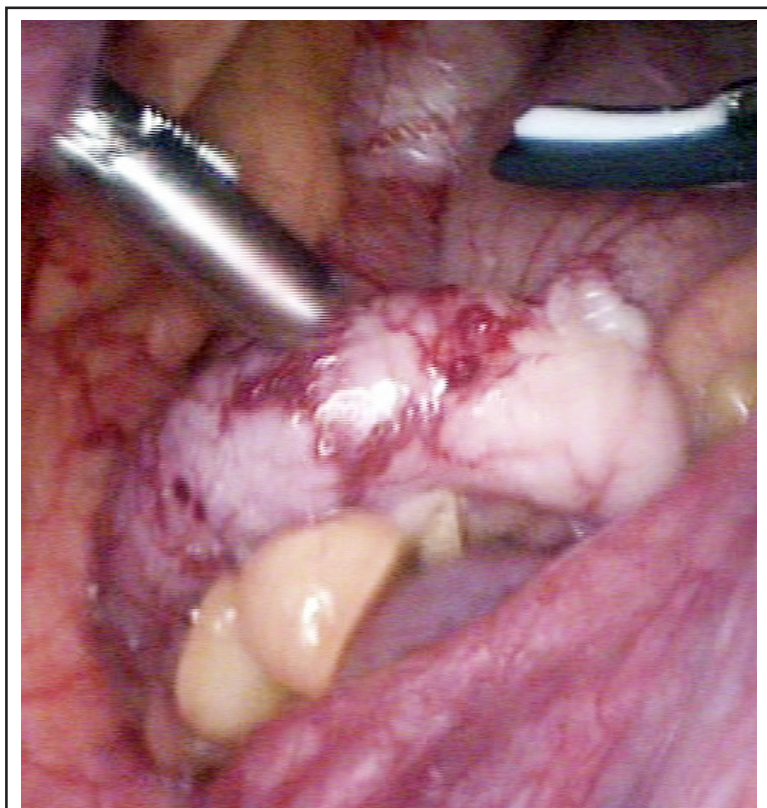

Figure 2: Right \& left hand instruments with inflamed appendix.

Fetal heart rate was $146 / \mathrm{min}$ in immediate postoperative period. There was no uterine activity in immediate postoperative period and no obstetric or surgical complication occurred. Patient was discharged after 72 h. Histopathological results confirmed inflamed appendix. Weekly follow ups were done and pregnancy progressed in satisfactory manner. At 38 weeks of gestation, patient delivered an alive female baby by elective LSCS which was uneventful.

\section{Discussion}

Initially, laparoscopic surgery in pregnancy was considered to be dangerous and was rather contraindicated. The reasons were many, including risk of injury to the pregnant uterus, elevating the $\mathrm{CO}_{2}$ level in the fetus, and an increase in spontaneous abortion.

Increased intra-abdominal pressure due to pneumoperitoneum and pressure from the gravid uterus on IVC may reduce the venous return which can lead to decreased cardiac output and to reduced uterine flow. A combination of reduced uterine flow and increased intra uterine pressure secondary to pneumoperitoneum may lead to fetal hypoxia $[5,6]$.

In our case, care was taken to maintain $30^{\circ}$ left lateral tilt with minimal reverse Tredelenburg position to maintain the adequate venous return. There has been apprehension about carbon dioxide pneumoperitoneum potentiating the respiratory acidosis in mother and the fetus [5, 6]. End tidal carbon dioxide monitoring has to be continued in the perioperative period to prevent acidosis.

Intra-abdominal pressure has to be kept to a minimum maintaining adequate visualization [6]. We could complete our case maintaining the pressure in range of 10-12 $\mathrm{mm} \mathrm{Hg}$. We used open technique for port placement to create pneumoperitoneum with no bowel injury or uterine injury. This technique has been advocated by many authors in literature as safest technique during pregnancy $[7,8]$.

Intra operative period of our case was uneventful and post-surgery fetal heart rate was normal and no uterine activity was detected so patient did not receive any tococlytic. Paracetamol was used for post-operative analgesia. Concerns regarding laparoscopy in pregnancy have been handled as surgical skills have increased with more experience and instrumentation has evolved. In fact, the laparoscope has made it possible to make a difficult diagnosis in pregnancy earlier, if one is comfortable with the use of this tool.

Laparoscopic appendectomy, in addition to its general advantage of a smaller incision, less postoperative pain, and earlier return to normal activity, offers other potential advantages for pregnant women. Laparoscopy can result in less manipulation of the uterus while obtaining optimum exposure of the surgical field and could reduce delays in diagnosis and treatment. It affords easier visualization and treatment of ectopically located appendix. Lower rates of dehiscence or herniation during labor are another potential benefit. Rapid return to full activity could reduce the frequency of maternal thrombosis and embolic events, which can be a major source of maternal mortality in some patients.

\section{Conclusion}

Laparoscopic surgery is proving to be safe in all trimesters, with no deleterious effect on mother or child. It provides pregnant patient with all the advantages of laparoscopy like less pain, faster recovery, cosmetic incision. Surgeon's experience is the most important determinant of a successful maternal-fetal outcome. 


\section{Acknowledgement}

Departments of Obstetrics \& Gynaecology, and Surgical Gastroenterology, Krishna Institute of Medical Sciences, Secunderabad, India.

\section{Conflicts of interest}

Authors declare no conflicts of interest.

\section{References}

[1] Kammerer WS. Nonobstetric surgery during pregnancy. Med Clin North Am. 1979; 63(6):1157-1164.

[2] Kort B, Katz VL, Watson WJ. The effect of nonobstetric operation during pregnancy. Surg Gynecol Obstet. 1993; 177(4):371-376.

[3] Radwan M, Maciolek-Blewniewska G, Malinowski A. Spontaneous heterotopic pregnancy and acute appendicitis treated by laparoscopy. Int J Gynaecol Obstet. 2007; 96(2):129.

[4] Rizzo AG. Laparoscopic surgery in pregnancy: long-term follow-up. J Laparoendosc Adv Surg Tech A. 2003; 13(1):1115.

[5] Constantino GN, Vincent GJ, Mukalian CG, Kliefoth WL Jr. Laparoscopic cholecystectomy in pregnancy. J Laparoendosc Surg. 1994; 4(2):161-164.

[6] Guildelines for laparoscopic surgery during pregnancy. Society of American Gastrointestinal Endoscopic Surgeons (SAGES). Surg Endosc. 1998; 12(2):189-190.

[7] Lanzafame RJ. Laparoscopic cholecystectomy during pregnancy. Surgery. 1995; 118(4):627-631.

[8] Hasson HM. Open laparoscopy: A report of 150 cases. J rep 